Check for updates

Cite this: RSC Adv., 2018, 8, 24740

Received 19th April 2018

Accepted 24th June 2018

DOI: $10.1039 / c 8 r a 03379 j$

rsc.li/rsc-advances

\section{Pre-clinical pharmacokinetic-pharmacodynamic modelling and biodistribution studies of donepezil hydrochloride by a validated HPLC method $\dagger$}

\author{
Kowthavarapu Venkata Krishna, ${ }^{a}$ Ranendra Narayana Saha, ${ }^{\mathrm{b}}$ Gautam Singhvi ${ }^{\mathrm{a}}$ \\ and Sunil Kumar Dubey (iD *a
}

A simple, sensitive and robust HPLC-PDA assay was developed and validated for rapid determination of donepezil hydrochloride (DNP), a potent acetylcholinesterase inhibitor in rat plasma and tissues. All biological samples were prepared by the solid-phase extraction method using loratadine as an internal standard. Separation of the analytes was achieved on a Waters Nova-Pak C18 column $(3.9 \times 150 \mathrm{~mm}, 4$ $\mu \mathrm{m})$ using an isocratic mobile phase of acetonitrile and ammonium formate $(\mathrm{pH} 6.4 ; 0.01 \mathrm{M})(62: 38 \% \mathrm{v} /$ v) at a flow rate of $1 \mathrm{~mL} \mathrm{~min}{ }^{-1}$. All validation parameter results were within the acceptable range described in the guidelines for bioanalytical method validation. The method showed linearity in the concentration range of $50-5000 \mathrm{ng} \mathrm{mL}^{-1}$ with LOD of $20 \mathrm{ng} \mathrm{mL}^{-1}$ and LLOQ of $50 \mathrm{ng} \mathrm{mL}^{-1}$. Moreover, the advantage of this method over previously published methods is the short analysis run time of 6 min in HPLC itself, alongside its application not only for plasma samples but also in tissues, with low LLOQ. The method was successfully applied for studying the compartmental pharmacokinetics, tissue distribution and pharmacodynamics. A two-compartmental micro model was statistically fitted for the assessment of pharmacokinetic parameters. The tissue distribution studies suggest that the kidneys, lungs and liver are the primarily responsible organs for metabolism and elimination of DNP. Pharmacodynamic studies were performed by measuring acetylcholinesterase inhibitory activity of DNP, which indicated that the pharmacokinetic and pharmacodynamic data are in correlation with each other.

\section{Introduction}

Globally, ageing is accompanied by an increasing substantial social and financial impact owing to ageing-related diseases. Dementia is one among them, a syndrome which leads to deterioration in cognition, thinking, behavior and ability to carry out daily routine work. ${ }^{1}$ As per an estimate, there were 46.8 million people worldwide living with dementia in 2015 and this number may reach 131.5 million by $2050 .{ }^{2}$ Alzheimer's Disease (AD) is the most typical cause of dementia and it contributes to $60-70 \%$ of the reported cases. As per a recent investigation by the Alzheimer's association, every 65 s one person in the United States (US) develops AD. It is a chronic and progressive neurodegenerative disease. There are drugs approved by the US Food and Drug Administration (US FDA) to condense its symptoms, which fall under acetylcholinesterase inhibitors (AChEI) and $N$ -

${ }^{a}$ Department of Pharmacy, Birla Institute of Technology and Science, Pilani (BITS-PILANI), Pilani Campus, Rajasthan, India, 333031.E-mail: skdubey@pilani. bits-pilani.ac.in; Tel: +918239703734

${ }^{b}$ Department of Biotechnology, Birla Institute of Technology and Science, Pilani (BITSPILANI), Dubai Campus, Dubai, UAE

$\dagger$ Electronic supplementary information (ESI) available. See DOI: 10.1039/c8ra03379j
methyl-D aspartate (NMDA) receptor antagonists. Tacrine was the first AChEI approved by the FDA and later it was withdrawn due to its side effects. ${ }^{3}$ Second generation AChEIs are DNP, galantamine and rivastigmine. Memantine which belongs to NMDA receptor antagonist was approved by FDA for the treatment of moderate and severe $\mathrm{AD}^{\mathbf{4 , 5}}$ All these drugs just delay the progression of the disease, dementia cannot be cured. ${ }^{6,7}$ At present the aim of the treatment is to maintain the quality of life as long as possible. DNP is effective in the treatment of cognitive impairment and memory loss in patients with AD. Moreover, due to the immense therapeutic potential and pharmacological activities of DNP, it is essential to develop a quick and accurate quantification method of DNP for conducting biostudies.

To the best of our knowledge, none of the methods have been applied either for estimation of DNP after intravenous (i.v.) administration or for compartmental pharmacokinetics, tissue distribution and pharmacodynamic studies. However, some methods have been reported in literature (Table 1), which are having more run time and require large sample volume with either a complex sample preparation procedure or use of sophisticated instruments like LC-MS/MS that hamper routine analysis for various applications. Abonassif, et al. developed a HPLC-RF method for the estimation of DNP in human plasma using a sample volume of $1000 \mu \mathrm{L}$ with a total run time of 
Table 1 Examples of extraction procedures and analytical techniques for estimation of DNP in biological samples ${ }^{a}$

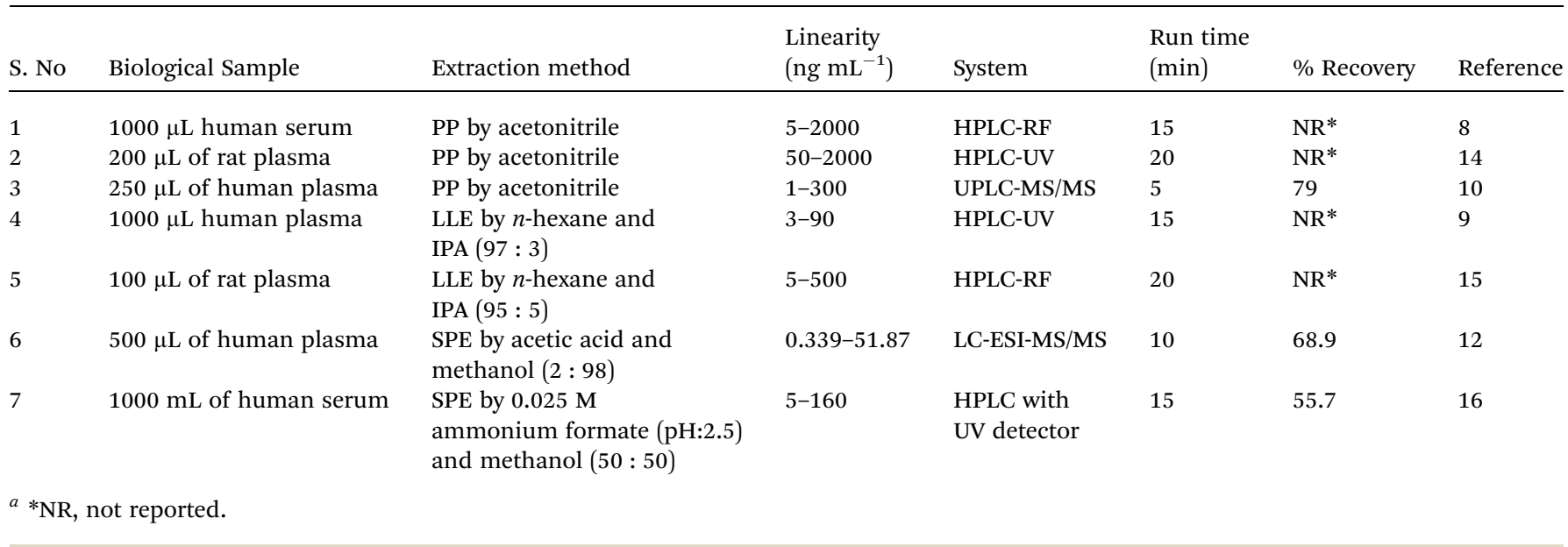

15 min, using protein precipitation technique (PP) by acetonitrile (ACN) as extracting solvent. ${ }^{8}$ Furukori, et al. have reported a HPLC-UV method using liquid-liquid extraction (LLE) process by $n$-hexane and IPA $(97: 3)$, with a run time of 15 min and sample volume $1000 \mu \mathrm{L}$ of human plasma. ${ }^{9}$ A simultaneous method has also been developed for the estimation of DNP and memantine in plasma. ${ }^{10} \mathrm{~A}$ UPLC-MS/MS method has been reported for the estimation of DNP in human serum, using PP by ACN. ${ }^{11}$ Another study was performed using LC-ESI-MS/MS with a sample volume of $500 \mu \mathrm{L}$ of human plasma, using solid-phase extraction (SPE) at a total run time of $10 \mathrm{~min} .{ }^{12}$ LC-MS/MS method is highly recommended procedure, significantly enhances the sensitivity of the method; but maintenance cost of the instrument is more, requires trained personnel and also not available in every research laboratory. However, DNP has been reported to be administered at a dose ranging from $5-10 \mathrm{mg}$ $\mathrm{kg}^{-1}$ in humans. ${ }^{13}$ Hence, the quantification upto $50 \mathrm{ng} \mathrm{mL}^{-1}$ is highly sufficient, HPLC based methods are equally helpful in estimation of DNP in pharmacokinetic samples. Moreover, the advantage of this method over previously published methods is the short analysis run time of 6 min in HPLC itself, its application not only for plasma samples but also in tissues and pharmacodynamic study.

The present work describes method development and validation details for quantification of DNP in rat plasma and tissues within the range of $50-5000 \mathrm{ng} \mathrm{mL}^{-1}$ and elucidating the compartmental pharmacokinetics, tissue distribution and pharmacodynamic profiles. The proposed method has been developed using solid-phase extraction (SPE) method using methanol $(2 \mathrm{~mL})$ as an eluting solvent, and with a total run time of $6 \mathrm{~min}$. Loratadine (LRD) was selected as internal standard (I.S) (Fig. 1). Complete validation was carried out including selectivity, lower limit of quantification (LLOQ), limit of detection (LOD), precision, accuracy, carry over effect, dilution integrity and stability as per guidelines on bioanalytical method validation. Stability studies were performed to determine the stability of stock solutions and in plasma samples that were exposed to different storage conditions which includes freezethaw, autosampler, bench top, short-term and long-term storage. Moreover, using this method we have generated a complete pharmacokinetic profile for DNP in rats. Hereby we report a new HPLC-PDA method for the estimation of DNP in rat plasma and in other biological tissues also. In addition to this, we also explored pharmacodynamic studies of DNP by estimation of acetylcholinesterase (AChE) levels.

\section{Materials and methods}

\subsection{Chemicals, materials and reagents}

DNP and LRD standards were kind gift samples from Vasudha Pharma Chem Limited (Hyderabad, India). ACN, methanol (HPLC grade) and sodium phosphate were procured from Merck Limited (Mumbai, India). Ammonium formate, acetylthiocholine iodide and 5,5'-dithiobis-(2-nitrobenzoic acid) (DTNB) were procured from Sigma Aldrich (St. Louis, MO, USA). Solid-phase cartridges, Clearnert PEP-3 SPE was procured from Agela Technologies (Wilmington, USA). Bovine serum albumin (BSA) was purchased from Sisco Research Laboratories Pvt. Ltd. (Mumbai, India). Water was produced by millipore Milli-Q Plus water treatment system (Millipore Bedford Corp., Bedford, MA, USA).

\subsection{Experimental animals}

All experimental animals (Wistar rats; male; 8-10 weeks; weighing around $200-220 \mathrm{~g}$ ), were housed in polyacrylic cages, and all procedures involving sample collection and their care were conducted in conformity with the institutional guidelines that are in compliance with Institutional Animal Ethics Committee (IAEC) of BITS-Pilani university with approved protocol (IAEC/RES/22/05). All animals were housed in a temperature $\left(20-22^{\circ} \mathrm{C}\right)$ and humidity $(65 \%)$ controlled animal facility and maintained on a $12 / 12 \mathrm{~h}$ light/dark cycle. The temperature and relative humidity were recorded daily. Both feed and water were provided ad libitum throughout the acclimatization and study period. 


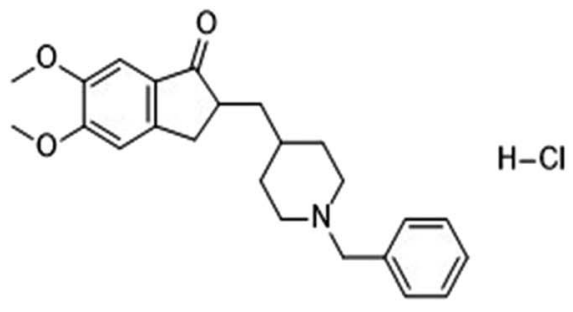

(I)

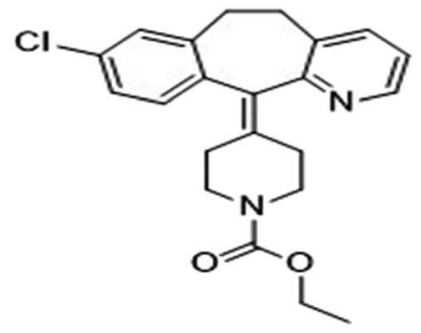

(II)

Fig. 1 Chemical structures of (I) DNP and (II) LRD.

\subsection{Liquid chromatographic conditions}

HPLC analysis were performed on Shimadzu liquid chromatograph system (Kyoto, Japan) equipped with a binary pump (LC10AT), Photo Diode Array (PDA) detector (SPD-M20A), column oven (CTO-10AS) and auto sampler (SIL-HT, Shimadzu, Japan) was used to inject the samples. The HPLC system was equilibrated for approximately $30 \mathrm{~min}$ before starting of analysis and chromatography was carried out at $40 \pm 0.5{ }^{\circ} \mathrm{C}$. Eluents were monitored at a wavelength of $268 \mathrm{~nm}$ using a PDA detector. DNP and LRD were separated on Waters Nova-Pak C18 column $(3.9 \times$ $150 \mathrm{~mm}, 4 \mu \mathrm{m}$ ) with a mobile phase consisting of acetonitrile and ammonium formate ( $\mathrm{pH} 6.4 ; 0.01 \mathrm{M})(62: 38 \% \mathrm{v} / \mathrm{v})$ in an isocratic mode at a flow rate of $1 \mathrm{~mL} \mathrm{~min}^{-1}$. The injection volume was $50 \mu \mathrm{L}$ and retention time for DNP and LRD were 3.31 and $3.99 \mathrm{~min}$ respectively. Control of hardware, data acquisition and elaboration were performed using LC solution software version 1.24 SP1.

\subsection{Preparation of stock solutions, calibration curve standards (CS) and quality control (QC) samples}

Standard stock solution of DNP was prepared by dissolving accurately weighed amount in methanol to obtain a final concentration of $5 \mathrm{mg} \mathrm{mL} \mathrm{m}^{-1}$. Further, same volumes of DNP

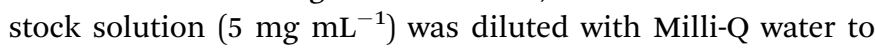
make $400 \mu \mathrm{g} \mathrm{mL}{ }^{-1}$ working stock solution. From $400 \mu \mathrm{g} \mathrm{mL}^{-1}$ working stock solution, working standard solutions of 1, 2, 6, 20, 40, 70 and $100 \mu \mathrm{g} \mathrm{mL} \mathrm{me}^{-1}$ were prepared by serial dilutions in Milli-Q water. The concentrations of working QC standard solutions were prepared as 1.6, 3 and $80 \mu \mathrm{g} \mathrm{mL}^{-1}$. CS and QC samples were prepared by spiking with $10 \mu \mathrm{L}$ of corresponding working standard solutions in $190 \mu \mathrm{L}$ of blank rat plasma. The final CS were prepared as 50, 100, 300, 1000, 2000, 3500 and $5000 \mathrm{ng} \mathrm{\textrm {mL } ^ { - 1 }}$ in plasma matrix. The QC were prepared by using QC standard solutions at four concentration levels, such as limit of quantification (LOQQC, $50 \mathrm{ng} \mathrm{mL}^{-1}$ ); low QC (LQC, 80 $\mathrm{ng} \mathrm{mL}^{-1}$ ), medium QC (MQC, $1500 \mathrm{ng} \mathrm{mL}^{-1}$ ) and high QC (HQC, $4000 \mathrm{ng} \mathrm{mL}^{-1}$ ). All the stock and working solutions were stored in the refrigerator at $-20{ }^{\circ} \mathrm{C}$ till analysis.

\subsection{Sample preparation}

Several extraction techniques were tested, such as protein precipitation with organic solvents (methanol, acetonitrile) and by liquid-liquid extraction using dichloromethane, $n$-hexane : IPA (97:3) and $n$-hexane : IPA (95:5). These procedures allow good recovery for IS, but plasma interference was observed with low recovery of analyte.

SPE method was also tested in order to reduce solvent consumption, maximize the analytes recovery, and to optimize the sample clean-up process. A $200 \mu \mathrm{L}$ aliquot of plasma sample containing DNP was taken in $2 \mathrm{~mL}$ capacity of polypropylene disposable tube, followed by the addition of $20 \mu \mathrm{L}$ of $100.0 \mu \mathrm{g}$ $\mathrm{mL}^{-1}$ of LRD (I.S) solution (I.S solution was prepared in ACN) and was vortexed for $1 \mathrm{~min}$. Then $200 \mu \mathrm{L}$ of ammonium formate buffer was added and vortexed for 2 min on a vortex mixer. The samples were then loaded into the SPE cartridges using a semiautomated SPE system (ESI; Table S1†). The SPE eluents were collected in glass tubes and evaporated to dryness at $40 \pm 0.5^{\circ} \mathrm{C}$ under a gentle stream of nitrogen gas. The residue was reconstituted with $200 \mu \mathrm{L}$ of mobile phase and vortexed for $30 \mathrm{~s}$. Finally, $50 \mu \mathrm{L}$ of sample was injected into HPLC through autoinjector for quantification.

\subsection{Method validation procedures}

The proposed method was validated as per guidelines US FDA and European Medical Agency guidelines of bioanalytical method validation. ${ }^{17,18}$

2.6.1 System suitability. System suitability is typically a system performance test, which was carried out by injecting the same concentration sample by six times for checking the column efficiency, reproductivity and resolution. It was performed to verify the holistic function of the chromatography system on a day-to-day basis.

2.6.2 Selectivity. The selectivity of the method was carried out to evaluate potential chromatographic interference from rat plasma matrix at retention time (RT) of the drug and IS. The rat blank plasma samples were collected randomly from selected six different Wistar rats and analyzed as per described chromatographic conditions.

2.6.3 Linearity and calibration curve. The calibration curve of an analyte (DNP) was prepared using six calibration standards in a range of 50 to $5000 \mathrm{ng} \mathrm{mL}^{-1}$. Six calibration curves were prepared for plasma and tissue samples by plotting peak area ratios (drug/I.S) on $Y$ axis versus nominal plasma concentrations on $X$-axis. Highest calibration standard sample (ULOQ, $5000 \mathrm{ng} \mathrm{mL} \mathrm{m}^{-1}$ ) was 100 times less than the lowest limit of

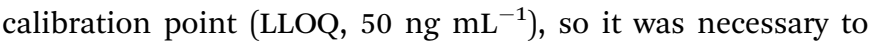
perform weighted linear regression on calibration data. All the different weighting factors were applied to the data obtained from least-squares regression analysis and the best weighting 
factors were chosen according the percentage relative error (\% $\mathrm{RE})$.

2.6.4 Limit of detection (LOD) and lower limit of quantitation (LLOQ). The limit of detection (LOD) is defined as the lowest concentration of analytes that can be detected and differentiated from the noise level.

The lower limit of quantitation (LLOQ) is defined as the lowest concentration of analytes that can be quantified with accepted accuracy and precision recommendations (not exceeding $\pm 20 \%)$.

LOD and LLOQ were determined by using signal to noise ratio method. First the signal to noise ratio was checked for standard samples at system suitability step. LOD and LLOQ were calculated based on eqn (1). Desired S/N values for LOD was 3 and for LLOQ was 10.

Concentration of LOQ and LOD

$$
=\frac{\text { Concentration of Standard }}{\frac{\mathrm{S}}{\mathrm{N}} \text { value of Standard }} \times \text { Desired } \frac{\mathrm{S}}{\mathrm{N}} \text { value }
$$

Generally, LLOQ is the first point in calibration curve and analyzed plasma samples by spiking with LLOQ concentration in six replicates $(n=6)$.
2.6.5 Precision and accuracy. The intra-day and inter-day assay precision and accuracy were determined by analyzing six replicates at three different QC levels (LQC, MQC, HQC) as described in Section 2.4 and LLOQ. The intra-day assay precision and accuracy were determined in six replicates by analyzing samples on same day, while inter-day assay precision and accuracy were determined in six replicates by analyzing each QC and LLOQ samples on five different days. The acceptance criteria for intra and inter-day precision (RSD, \%) was limited to $\leq 15 \%$ and accuracy was required to be limited within $\pm 15 \%$ except for LLOQ, where it should not exceed $\pm 20 \%$ for accuracy and precision.

2.6.6 Recovery. The percentage recovery of DNP through SPE were determined by comparing the peak area of analyte spiked plasma QC samples with those of unextracted neat standards that is standard solution with equivalent concentrations.

2.6.7 Carry over effect and dilution integrity. Carry over effect was determined by injecting highest calibration standard sample (ULOQ, $5000 \mathrm{ng} \mathrm{mL}^{-1}$ ) followed by blank sample. As per guidelines, the sample dilution must be performed to ensure the integrity of plasma samples. In dilution integrity, blank plasma was spiked with 2 times higher than the ULOQ concentration (10 $000 \mathrm{ng} \mathrm{mL} \mathrm{m}^{-1}$ ) and was diluted 5 times and 10 times with blank plasma $(n=6)$ to obtain a concentration of $2000 \mathrm{ng} \mathrm{mL}^{-1}$ and $1000 \mathrm{ng} \mathrm{mL}^{-1}$. Dilutes samples were processed and analyzed with freshly spiked calibration curve in
(A)

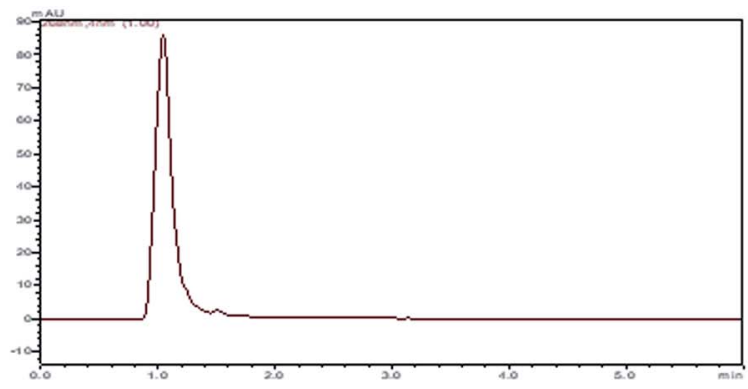

(C)

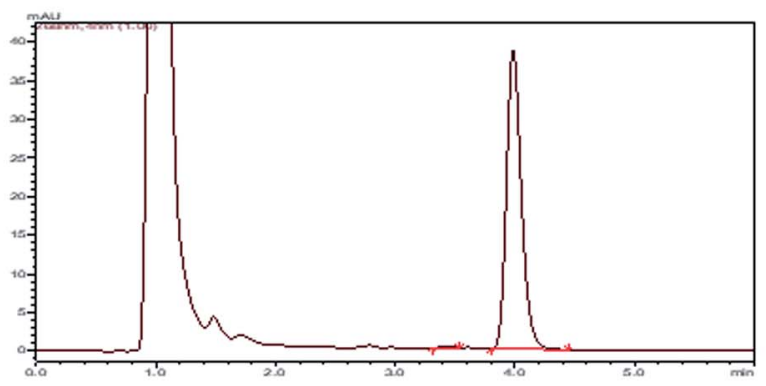

(E)

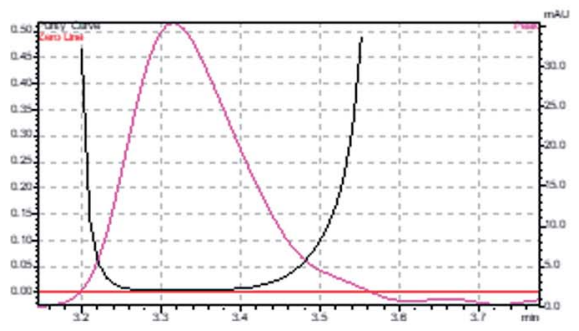

(B)

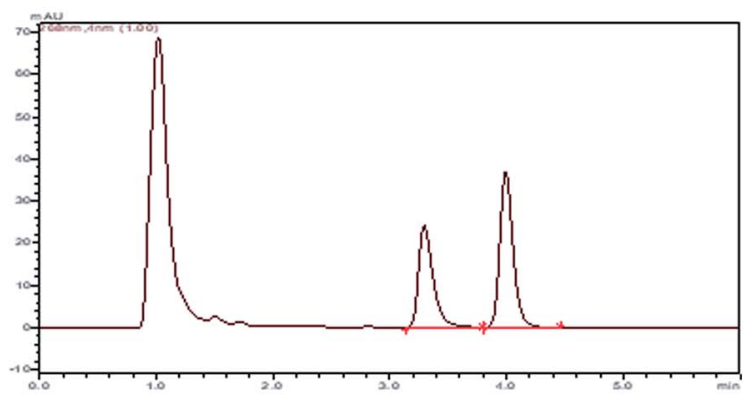

(D)

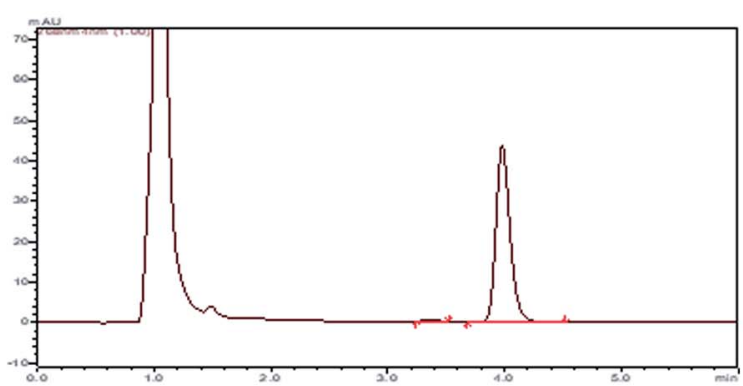

(F)

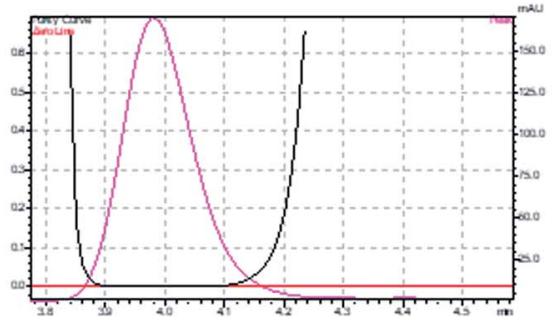

Fig. 2 HPLC chromatograms for (A) blank plasma, (B) calibration standard, (C) LOD (20 ng mL ${ }^{-1}$ ), (D) LLOQ (50 ng mL $\mathrm{m}^{-1}$ ), (E) peak purity index of DNP, (F) peak purity index of I.S. 
Table 2 Precision and accuracy data of back calculated concentrations of calibration standard samples of DNP in rat plasma $(n=6)^{a}$

\begin{tabular}{|c|c|c|c|c|c|}
\hline Component & $\begin{array}{l}\text { Linear equation and } \\
\text { coefficient of regression }\end{array}$ & $\begin{array}{l}\text { Nominal concentration } \\
\left(\mathrm{ng} \mathrm{mL} \mathrm{L}^{-1}\right)\end{array}$ & $\begin{array}{l}\text { Measured concentration } \\
\left(\text { Mean } \pm \mathrm{SD}, \mathrm{ng} \mathrm{mL}^{-1}\right)\end{array}$ & $\begin{array}{l}\text { Precision } \\
(\% \mathrm{CV})\end{array}$ & $\begin{array}{l}\text { Accuracy } \\
\text { (\% bias) }\end{array}$ \\
\hline \multirow[t]{4}{*}{ Plasma } & \multirow{4}{*}{$y=0.000384 x-0.0088, r^{2}=0.9999$} & 50 & $51.87 \pm 3.21$ & 6.19 & 3.74 \\
\hline & & 300 & $304.26 \pm 16.99$ & 5.58 & 1.42 \\
\hline & & 1000 & $999.58 \pm 2.96$ & 0.30 & -0.04 \\
\hline & & 2000 & $1983.08 \pm 12.60$ & 0.64 & -0.85 \\
\hline \multirow[t]{6}{*}{ Brain } & \multirow[t]{6}{*}{$y=0.0003 x-0.0058, r^{2}=0.9998$} & 50 & $55.26 \pm 1.15$ & 2.08 & 10.52 \\
\hline & & 300 & $289.54 \pm 15.48$ & 5.35 & -3.49 \\
\hline & & 1000 & $939.40 \pm 87.62$ & 9.33 & -6.06 \\
\hline & & 2000 & $1950.68 \pm 13.60$ & 0.70 & -2.47 \\
\hline & & 3500 & $3335.07 \pm 30.75$ & 9.18 & -4.71 \\
\hline & & 5000 & $4872.22 \pm 19.75$ & 0.41 & -2.56 \\
\hline & \multirow{2}{*}{$y=0.0003 x-0.0075, r^{2}=0.9991$} & 3500 & $3547.65 \pm 4.37$ & 0.12 & 1.36 \\
\hline & & 5000 & $5262.01 \pm 43.58$ & 0.83 & 5.24 \\
\hline \multirow[t]{6}{*}{ Lungs } & \multirow[t]{6}{*}{$y=0.0003 x-0.0099, r^{2}=0.9999$} & 50 & $56.78 \pm 4.23$ & 7.45 & 13.56 \\
\hline & & 300 & $316.62 \pm 28.83$ & 9.11 & 5.54 \\
\hline & & 1000 & $1041.39 \pm 93.03$ & 8.93 & 4.14 \\
\hline & & 2000 & $2168.05 \pm 106.81$ & 4.93 & 8.40 \\
\hline & & 3500 & $3749.94 \pm 206.25$ & 5.50 & 7.14 \\
\hline & & 5000 & $5372.00 \pm 291.26$ & 5.42 & 7.44 \\
\hline \multirow[t]{4}{*}{ Spleen } & \multirow[t]{4}{*}{$y=0.0003 x+0.0089, r^{2}=0.9996$} & 50 & $55.31 \pm 3.32$ & 6.00 & 10.62 \\
\hline & & 300 & $289.15 \pm 8.66$ & 2.99 & -3.62 \\
\hline & & 1000 & $1049.53 \pm 80.29$ & 7.65 & 4.95 \\
\hline & & 2000 & $2148.97 \pm 146.01$ & 6.79 & 7.44 \\
\hline \multirow[t]{6}{*}{ Liver } & \multirow[t]{6}{*}{$y=0.0003 x-0.0126, r^{2}=0.9999$} & 50 & $52.94 \pm 1.68$ & 3.17 & 5.88 \\
\hline & & 300 & $281.24 \pm 25.88$ & 9.20 & -6.25 \\
\hline & & 1000 & $935.92 \pm 29.60$ & 3.16 & -6.41 \\
\hline & & 2000 & $1880.22 \pm 135.81$ & 7.22 & -5.99 \\
\hline & & 3500 & $3240.65 \pm 18.66$ & 0.58 & -7.41 \\
\hline & & 5000 & $4703.54 \pm 5.48$ & 0.12 & -5.93 \\
\hline
\end{tabular}

${ }^{a} \mathrm{SD}$, standard deviation; CV, coefficient of variation.

plasma. The accuracy and precision values should be within $\pm 15 \%$.

2.6.8 Stability studies. Stability of analytes in plasma matrix were evaluated before and after subjecting to different conditions and temperatures that could encounter during regular analysis. Stability in plasma was evaluated in terms of freeze-thaw stability, bench top stability, short-term stability and autosampler stability. All stability studies were conducted in three replicates at each concentration of the three different QC levels (LQC, MQC, and HQC). Freeze thaw stability was performed after freezing $\left(-80 \pm 10^{\circ} \mathrm{C}\right.$ for $\left.48 \mathrm{~h}\right)$ and thawing QC samples for three consecutive cycles within 2 days. Bench top stability was analyzed at $25 \pm 2{ }^{\circ} \mathrm{C}$ for $24 \mathrm{~h}$, short-term stability was evaluated at $-80 \pm 10^{\circ} \mathrm{C}$ for 15 days and long-term stability was examined at $-80 \pm 10^{\circ} \mathrm{C}$ for 3 months were performed in rat plasma with all QC levels. Replicate injections of extracted plasma samples were analyzed after $48 \mathrm{~h}$ to estimate auto sampler stability.

All QC samples were extracted and quantified against fresh calibration curves and fresh QC samples. The acceptance criteria of accuracy and precision for all stability samples should be within $\pm 15 \%$.

\subsection{Pharmacokinetic study}

To investigate the developed method, pharmacokinetic studies of DNP was performed on young Wistar rats weighing around 200$220 \mathrm{~g}$. An i.v. administration, at a dose of $5 \mathrm{mg} \mathrm{kg}^{-1}$ of DNP were given to animals. After dosing, blood samples were collected in 
Table 3 Precision (\% CV) and accuracy (\% bias) of DNP in rat plasma samples at QC levels $(n=6)$

\begin{tabular}{|c|c|c|c|c|c|c|c|}
\hline \multirow[b]{2}{*}{ Level } & \multirow[b]{2}{*}{$\begin{array}{l}\text { Nominal Conc. } \\
\left(\mathrm{ng} \mathrm{mL}^{-1}\right)\end{array}$} & \multicolumn{3}{|l|}{ Inter-day } & \multicolumn{3}{|l|}{ Intra-day } \\
\hline & & $\begin{array}{l}\text { Measured Conc. } \\
\left(\text { Mean } \pm \mathrm{SD}, \mathrm{ng} \mathrm{mL}^{-1}\right)\end{array}$ & $\begin{array}{l}\text { Precision } \\
(\% \mathrm{CV})\end{array}$ & $\begin{array}{l}\text { Accuracy } \\
\text { (\% bias) }\end{array}$ & $\begin{array}{l}\text { Measured Conc. } \\
\left(\text { Mean } \pm \mathrm{SD}, \mathrm{ng} \mathrm{mL}^{-1}\right)\end{array}$ & $\begin{array}{l}\text { Precision } \\
(\% \mathrm{CV})\end{array}$ & $\begin{array}{l}\text { Accuracy } \\
\text { (\% bias) }\end{array}$ \\
\hline LLOQ & 50 & $53.54 \pm 2.43$ & 4.54 & 7.08 & $50.21 \pm 3.19$ & 6.35 & 0.42 \\
\hline LQC & 80 & $79.74 \pm 4.45$ & 5.58 & -0.33 & $77.51 \pm 5.36$ & 6.92 & -3.11 \\
\hline MQC & 1500 & $1543.40 \pm 14.82$ & 0.96 & 2.89 & $1513.29 \pm 22.85$ & 1.51 & 0.89 \\
\hline HQC & 4000 & $4025.35 \pm 25.97$ & 0.65 & 0.63 & $3926.75 \pm 65.42$ & 1.67 & -1.83 \\
\hline
\end{tabular}

$1.5 \mathrm{~mL}$ capacity of polypropylene disposable tubes for each time point at $0,0.083,0.166,0.5,0.75,1,3,6,9,12,15,18,24,30$ and $36 \mathrm{~h}$. Blood samples were collected from the retro-orbital plexus into heparinized micro centrifuge tubes at pre-determined time interval. Plasma samples were harvested by centrifuging the blood at $6000 \mathrm{rpm}$ for $15 \mathrm{~min}$ and stored at $-80 \pm 10{ }^{\circ} \mathrm{C}$ until analysis. DNP plasma concentration-time profiles were plotted.

\subsection{Pharmacokinetic modeling}

Pharmacokinetic parameters for DNP were performed by using compartmental analysis. Model selection was guided by visual inspection of the observed plasma profiles and Akaike's information(AIC) criterion. ${ }^{19}$ The lowest AIC value suggests best fit model. Various pharmacokinetic parameters such as concentration maximum $\left(C_{\max }\right)$, area under curve (AUC), volume of distribution in central compartment (V1), volume of distribution in peripheral compartment $(V 2)$, plasmatic clearance $(C l)$, intercompartmental clearance (CLD2), alpha half-life $\left(t_{1 / 2} \alpha\right)$, beta half-life $\left(t_{1 / 2} \beta\right)$, and elimination rate constants of two compartmental model (K10, K12, K21) were estimated Phoenix WinNonlin Certara $^{\mathrm{TM}}$ (Pharsight, U.S.A; version:8.0).

\subsection{Tissue distribution study in rats}

Wistar rats were randomly divided into 2 groups, one group as control and for the other group DNP was given i.v. at a dose of $5 \mathrm{mg} \mathrm{kg}^{-1}$. Tissues (brain, heart, lungs, kidney, spleen and liver) were promptly harvested at $0.166,0.75,2,6 \mathrm{~h}$ (three rats/time point) after the administration of dose and thoroughly rinsed in ice-cold saline to remove blood and other content and blotted dry with filter paper. An accurately weighed amount of each tissue samples were homogenized in 1:2 w/v of phosphate buffer saline solution by using tissue homogenizer. After homogenization, centrifugation was done at $10000 \mathrm{rpm}$ for $15 \mathrm{~min}$, clear supernatant was collected and stored at $-80{ }^{\circ} \mathrm{C}$ until analysis.

\subsection{Pharmacodynamic studies}

The levels of AChE and butyl cholinesterase are the biological markers for $\mathrm{AD}^{20}$ Cholinesterase inhibitors (ChEIs) enhances the breakdown of AChE in synaptic cleft, thus enhancing ACh levels. Pharmacodynamic effects of DNP on AChE activity in rats was explored. The estimation of AChE activity in plasma samples were performed as per method described by Ellman et $a l .{ }^{21} \mathrm{In}$ brief, the assay sample contained $0.05 \mathrm{~mL}$ of plasma, $3 \mathrm{~mL}$ of $0.01 \mathrm{M}$ sodium phosphate buffer ( $\mathrm{pH} 8), 0.10 \mathrm{~mL}$ of acetylthiocholine iodide and $0.10 \mathrm{~mL}$ of DTNB (Ellman reagent). The change in absorbance was measured immediately at $412 \mathrm{~nm}$ spectrophotometrically. Protein content in plasma samples was measured by the method of Lowry et al. ${ }^{22}$ using BSA $\left(1 \mathrm{mg} \mathrm{mL}{ }^{-1}\right)$ as a standard. Results were calculated using molar extinction coefficient of chromophore $\left(1.36 \times 104 \mathrm{M}^{-1} \mathrm{~cm}^{-1}\right)$ and expressed as nanomoles per milligram protein. ${ }^{23}$ Maximal AChE inhibition time of DNP was estimated. ${ }^{24,25}$

\section{Results}

\subsection{Method development}

3.1.1 Optimization of liquid chromatographic conditions. A methodological approach was followed for the method development so as to obtain analyte in less time using simplest possible chromatographic conditions for obtaining an appropriate recovery, symmetric peaks and high resolution of the drugs. For that, liquid chromatographic conditions such as choice of mobile phase, composition of mobile phase, $\mathrm{pH}$ of buffer, column selection, flow rate and injection volume were optimized (ESI; Table S2 $)$ ). After successive optimization, acetonitrile-ammonium formate ( $\mathrm{pH}: 6.4 ; 0.01 \mathrm{M})$ was selected as mobile phase which gave best peak shape and good peak intensities. Different columns were used to optimize better resolution, selectivity and retention time. Waters Nova-Pak C18 column $(3.9 \times 150 \mathrm{~mm}, 4 \mu \mathrm{m})$ with acetonitrile-ammonium formate (pH: 6.4; $0.01 \mathrm{M}$ ) mobile phase in ratio of $62: 38 \% \mathrm{v} / \mathrm{v}$

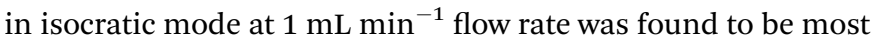
suitable for DNP analysis with a total run time of $6 \mathrm{~min}$. The injection volume was $50 \mu \mathrm{L}$ and optimized retention time for DNP and LRD (I.S) were 3.31 and $3.99 \mathrm{~min}$ respectively at a wavelength $268 \mathrm{~nm}$.

Table 4 Absolute recoveries (\%) of DNP in rat plasma samples from QC levels ${ }^{a}$

\begin{tabular}{lllll}
\hline & & \multicolumn{2}{l}{ Recovery $(\%)$} \\
\cline { 3 - 5 } Level & $\begin{array}{l}\text { Nominal concentration } \\
\left.(\mathrm{ng} \mathrm{mL})^{-1}\right)\end{array}$ & $n$ & $\begin{array}{l}\text { Mean } \pm \\
\text { SD }(n=3)\end{array}$ & $\%$ CV \\
\hline LLOQ & 50 & 3 & $80.22 \pm 1.44$ & 1.80 \\
LQC & 80 & 3 & $80.28 \pm 1.18$ & 1.47 \\
MQC & 1500 & 3 & $78.68 \pm 1.62$ & 2.06 \\
HQC & 4000 & 3 & $80.28 \pm 1.95$ & 2.43 \\
& Mean & 12 & $79.86 \pm 1.55$ & 1.94
\end{tabular}

${ }^{a} n$, number of samples; SD, standard deviation; CV, coefficient of variation. 
Table 5 Stability of DNP in rat plasma at QC levels

\begin{tabular}{|c|c|c|c|c|}
\hline Stability & $\begin{array}{l}\text { Nominal concentration } \\
\left(\mathrm{ng} \mathrm{mL} \mathrm{m}^{-1}\right)\end{array}$ & $\begin{array}{l}\text { Measured Concentration } \\
\left(\text { ng } \mathrm{mL}^{-1}\right) \pm \mathrm{SD}\end{array}$ & $\begin{array}{l}\text { Precision } \\
(\% \mathrm{CV})\end{array}$ & $\begin{array}{l}\text { Accuracy } \\
\text { (\% bias) }\end{array}$ \\
\hline \multirow[t]{3}{*}{$0 \mathrm{~h}$ (for all) } & 50 & $53.54 \pm 2.43$ & 4.54 & 7.08 \\
\hline & 1500 & $1543.40 \pm 14.82$ & 0.96 & 2.89 \\
\hline & 4000 & $4025.35 \pm 25.97$ & 0.65 & 0.63 \\
\hline \multirow[t]{2}{*}{ Autosampler (48 h) } & 50 & $51.72 \pm 2.60$ & 5.03 & 3.44 \\
\hline & 4000 & $3972.38 \pm 5.35$ & 0.13 & -0.69 \\
\hline \multirow[t]{4}{*}{ Bench-top (24 h, RT) } & 50 & $54.12 \pm 1.42$ & 2.62 & 8.24 \\
\hline & 80 & $84.49 \pm 4.94$ & 5.85 & 5.61 \\
\hline & 1500 & $1548.91 \pm 7.95$ & 0.51 & 3.26 \\
\hline & 4000 & $3951.87 \pm 24.88$ & 0.63 & -1.20 \\
\hline Freeze-thaw $\left(-80^{\circ} \mathrm{C}, 3\right.$ cycle $)$ & 50 & $54.84 \pm 2.50$ & 4.56 & 9.68 \\
\hline & 80 & $78.01 \pm 2.62$ & 3.36 & -2.49 \\
\hline & 1500 & $1414.08 \pm 54.99$ & 3.89 & -5.73 \\
\hline & 4000 & $3722.16 \pm 12.29$ & 0.33 & -6.95 \\
\hline \multirow{4}{*}{$\begin{array}{l}\text { Long-term }\left(-80^{\circ} \mathrm{C}, 3\right. \\
\text { months })\end{array}$} & 50 & $47.81 \pm 2.47$ & 5.17 & -4.38 \\
\hline & 80 & $84.54 \pm 2.78$ & 3.29 & 5.62 \\
\hline & 1500 & $1337.55 \pm 12.59$ & 0.94 & -10.83 \\
\hline & 4000 & $3655.47 \pm 13.88$ & 0.38 & -8.61 \\
\hline
\end{tabular}

3.1.2 Optimization of plasma sample preparation. Once the chromatographic conditions were optimized, extraction recovery of analyte was optimized by selecting an appropriate extraction method. The plasma sample clean-up procedure was also an important step in the method as it is directly proportional to sensitivity and selectivity of method. Higher recovery of analyte from plasma matrix can be obtained by minimum sample preparation processing, as well as proper choice of extraction method. Various problems have been encountered during the method optimization. Different methods for extracting drug from plasma matrix have been tried such as protein precipitation (with ACN and methanol), liquid-liquid extraction (with hexane, methylene chloride, IPA) and solidphase extraction (SPE) (ESI; Table S3†). Out of all, SPE was found to produce higher recoveries, reproductivity and cleaner chromatogram.

\subsection{Method validation}

3.2.1 System suitability, selectivity and chromatographic separation. By performing the system suitability test, we conformed that system was working fine and it showed reproducibility with proper resolution. In described chromatographic condition, analytes were successfully separated with optimum retention time less than $6 \mathrm{~min}$. (DNP and I.S retention times were 3.31 and 3.99). The sample clean-up procedure was so selective as there was no significant plasma matrix interference at retention time of analyte. A representative chromatogram of blank plasma, (plasma sample without analyte and IS), plasma sample with analyte and IS, LOD plasma sample $\left(20 \mathrm{ng} \mathrm{mL}^{-1}\right)$

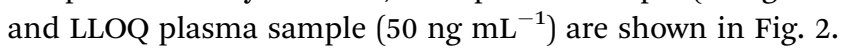

3.2.2 Linearity, calibration curve, LOD, LLOQ. All the calibration standard curves for plasma and tissue samples showed linearity and reproducibility over the selected concentration range of 50-5000 $\mathrm{ng} \mathrm{mL}{ }^{-1}$ with $r^{2}$ values more than 0.9999. The $r^{2}$ values, slopes and intercepts were calculated from five intra and inter day calibration curves using weighted linear regression analysis (1/var, $\left.1 / x, 1 / x^{2}, 1 / \sqrt{x}, 1 / y, 1 / y^{2}, 1 / \sqrt{y}\right)$ wherein, best weighting factors were chosen as $1 / x^{2}$ as these showed minimum percentage relative error (\% RE) (ESI; Table S4 $\dagger$ ). The observed mean back calculated concentrations with accuracy (\% bias) and precision (\% CV) are presented in Table 2. At LLOQ $(n=6)$ accuracy (\% bias) was in the range of $3.74 \%$ with a \% CV of $6.19 \%$. LOD and LLOQ were established as $20 \mathrm{ng} \mathrm{mL}^{-1}$ and $50 \mathrm{ng} \mathrm{mL}^{-1}$ respectively.

Table 6 Pharmacokinetic parameters for DNP after i.v. bolus (5 mg $\left.\mathrm{kg}^{-1}\right)$ administration in rats $(n=4)$

\begin{tabular}{lc}
\hline Pharmacokinetic parameters & DNP $5 \mathrm{mg} \mathrm{kg}^{-1} ;$ i.v. \\
\hline AIC of one compartment & $129.86 \pm 2.61$ \\
AIC of two compartment & $114.06 \pm 5.36$ \\
$C_{0}\left(\mathrm{ng} \mathrm{mL}^{-1}\right)$ & $468.02 \pm 11.84$ \\
AUC $\left.0-\infty(\mathrm{ng} \mathrm{h} \mathrm{mL})^{-1}\right)$ & $4655.05 \pm 352.53$ \\
V1 $\left(\mathrm{mL} \mathrm{kg}^{-1}\right)$ & $10697.06 \pm 274.35$ \\
V2 $\left(\mathrm{mL} \mathrm{kg}^{-1}\right)$ & $4424.51 \pm 816.59$ \\
$\mathrm{Cl}\left(\mathrm{mL} \mathrm{h}^{-1} \mathrm{~kg}\right)$ & $1087.58 \pm 89.00$ \\
$\mathrm{CLD} 2\left(\mathrm{~mL} \mathrm{~h}^{-1} \mathrm{~kg}\right)$ & $2070.95 \pm 599.09$ \\
$T_{1 / 2} \alpha(\mathrm{h})$ & $1.21 \pm 0.46$ \\
$T_{1 / 2} \beta(\mathrm{h})$ & $10.43 \pm 0.53$ \\
$\mathrm{MRT}(\mathrm{h})$ & $13.94 \pm 0.95$ \\
$K 10\left(\mathrm{~h}^{-1}\right)$ & $0.101 \pm 0.0058$ \\
$K 12\left(\mathrm{~h}^{-1}\right)$ & $0.196 \pm 0.06$ \\
$K 21\left(\mathrm{~h}^{-1}\right)$ & $0.554 \pm 0.24$
\end{tabular}




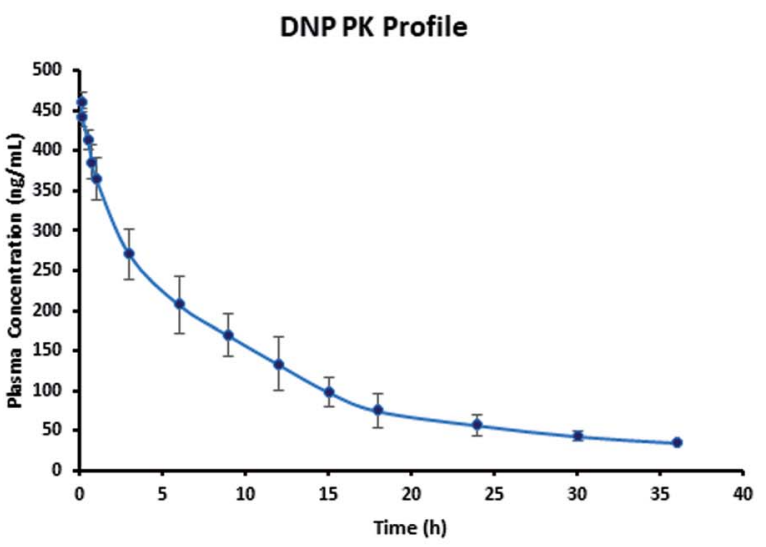

(A)

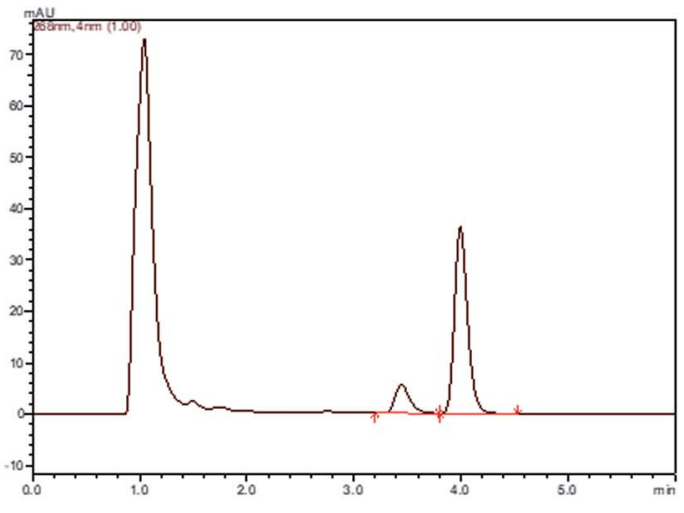

(B)

Fig. 3 (A) Plasma concentration-time profile of DNP (mean $\pm S D, n=4$ ) and (B) representative chromatogram of plasma sample obtained after $30 \mathrm{~min}$ of post drug administration.**In these studies, DNP was administered by i.v. bolus at a single dose of $5 \mathrm{mg} \mathrm{kg}^{-1}$ each in rat $(n=4)$.

3.2.3 Precision and accuracy. The intra and inter day accuracy, precision data obtained from QC samples at four different concentration levels (LLOQC, LQC, MQC, HQC) are shown in Table 3. The inter and intra-day precision values did not exceed $6.92 \%$. The inter and intra-day $\%$ bias ranged from -3.11 to $7.08 \%$. All the values were within the recommendation of international guidelines.

3.2.4 Recovery, carry over, dilution integrity. The mean recovery values from rat plasma samples are listed in Table 4 . The mean absolute recovery for DNP was found to be $79.86 \pm$ $1.55 \%(n=12)$. No carry over effect was observed, there was absence of peaks of analytes in blank sample was injected after ULOQ. Dilution integrity was carried out by diluting 5 times and 10 times with the blank plasma $(n=6)$. The accuracy value after 5 times and 10 times dilution were found to be $98.60 \pm 3.47$ and $101.75 \pm 2.81$ respectively.

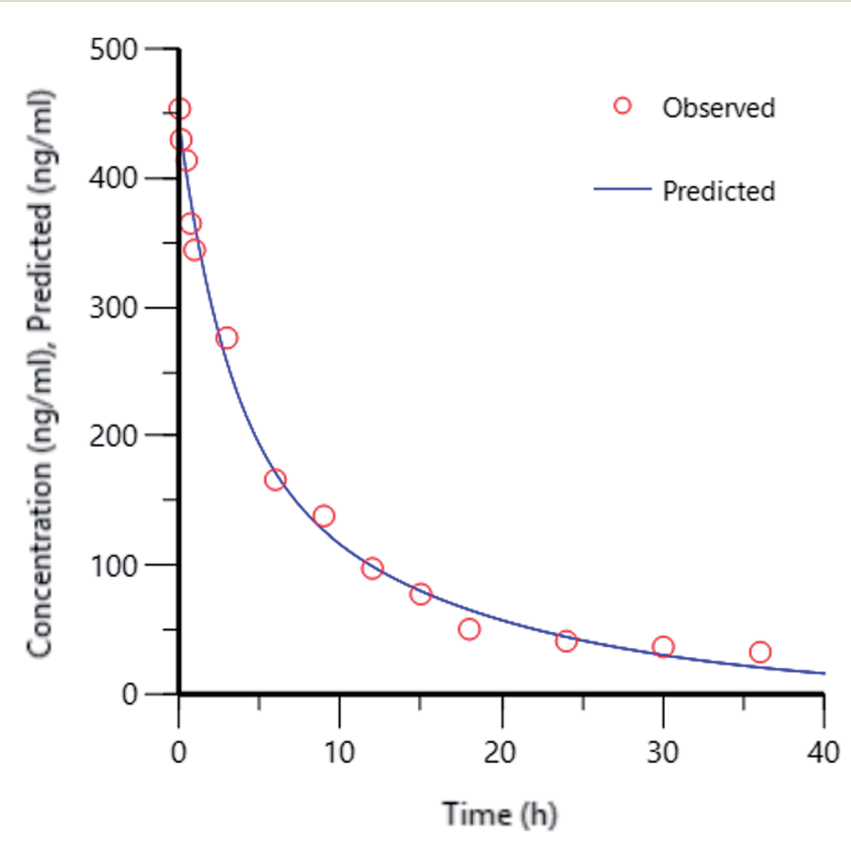

Fig. 4 Concentration plot of observed versus predicted.
3.2.5 Stability studies. The stability studies for DNP were performed as per the procedure described in Section 2.6.8. Different stability studies such as stock solution stability, freeze-thaw stability, bench top stability, short-term stability and autosampler stability results indicated that DNP was stable under different storage conditions that may be faced during routine study sample analysis and there was no significant degradation observed (Table 5).

\subsection{Pharmacokinetic study in rats}

The developed assay was productively implemented for the pharmacokinetic study of DNP after the i.v. administration of DNP at a dose of $5 \mathrm{mg} \mathrm{kg}^{-1}$ in Wistar rats. The calibration range (50-5000 $\mathrm{ng} \mathrm{mL}^{-1}$ ) of this assay method fitted to estimate all pharmacokinetic samples. The various pharmacokinetic parameters of DNP including observed maximum concentration $\left(C_{0}\right)$, half-life $\left(t_{1 / 2}\right)$ and area under the curve $\left(\mathrm{AUC}_{0-t}\right)$ were calculated using compartmental pharmacokinetic analysis and represented in the Table 6 . Mean \pm SD plasma concentration versus time profile of DNP is shown in Fig. 3.

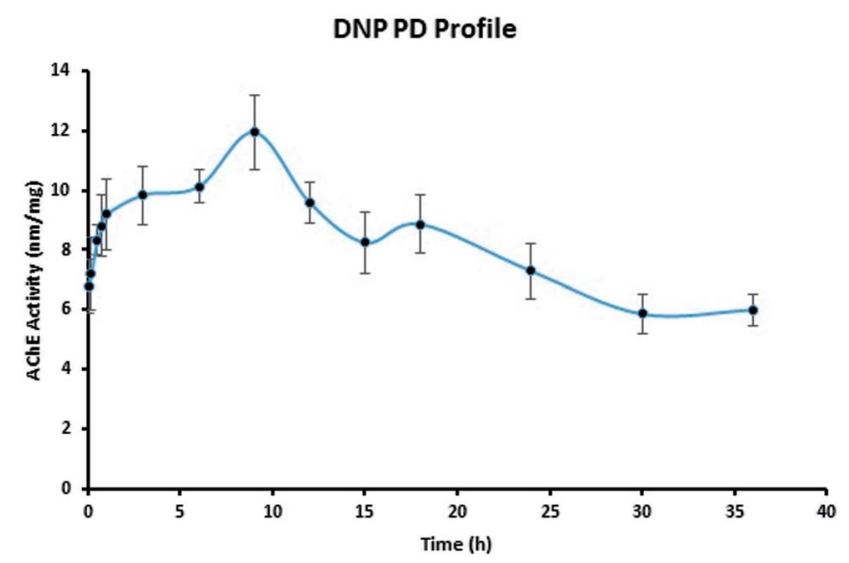

Fig. 5 Pharmacodynamic profile of DNP. 

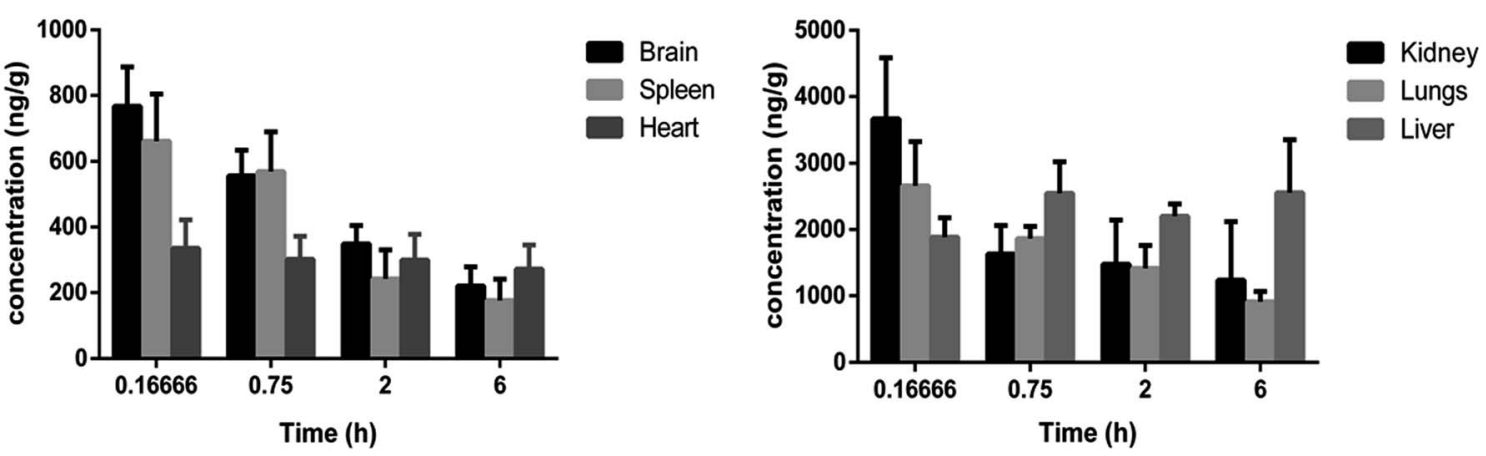

Fig. 6 Concentration (mean \pm SD) levels of DNP in rat tissues at $0.1666,0.75,2$ and 6 h.****In these studies, DNP was administered by i.v. bolus at a single dose of $5 \mathrm{mg} \mathrm{kg}^{-1}$ each in rat (three/time point).

\subsection{Pharmacokinetic modeling}

Experimental plasma concentration-versus-time profiles were fitted to a two-compartmental micro model with i.v. bolus input and linear first order elimination from the central compartment using iterative weighted non-linear least squares regression using Phoenix WinNonlin Certara ${ }^{\mathrm{TM}}$ (Pharsight, U.S.A; version:8.0). The observed versus predicted concentrations did not differ from the line of identity, and no bias was observed (Fig. 4). DNP have shorter distribution half-life $\left(T_{1 / 2} \alpha\right)$ of $1.21 \mathrm{~h}$, which indicates rapid distribution from systemic circulation into the extravascular tissue spaces. Moreover, smaller elimination rate constant $\left(K_{10}\right)$ of $0.1 \mathrm{~h}$ from central compartment, longer elimination half-life $\left(T_{1 / 2} \beta\right)$ of 10.43 indicates behaved slow distribution and elimination characteristics.

\subsection{Pharmacodynamic study}

To examine the pharmacodynamic changes of DNP, the AChE inhibitory activity was determined (Fig. 5). Results have shown the correlation between pharmacokinetic profile, as the inhibitory activity was observed till $9 \mathrm{~h}$ thereafter, decrease in activity was noticed. The maximal effect of AChE inhibition was at $9.5 \mathrm{~h}$, it clearly indicates the action of the DNP was matching with the pharmacokinetic data. Therefore, the established data in this study was reliable and highly suitable for pharmacokineticpharmacodynamic modeling.

\subsection{Tissue distribution study}

Tissue distribution study was carried out to identify the major distribution sites of DNP after i.v. administration at a dosage of $5 \mathrm{mg} \mathrm{kg}{ }^{-1}$. The distribution of DNP in the various rat tissues are represented in Fig. 6 and the representative of chromatographs are shown in Fig. S1. $\dagger$ The results demonstrated that DNP has exhibited wide range of distribution to tissues within the time course examined. As per the data obtained, the DNP concentration in various organs showed the following order: kidney $>$ lungs $>$ liver $>$ brain $>$ spleen $>$ heart. By comparing organ and plasma samples, the distribution level in the kidney was 7.95 folds higher than that in plasma, 5.77 folds higher in the lungs than that in plasma and 4.09 folds higher in the liver than that in plasma. This clearly suggests that kidney, lungs and liver were the organs primarily involved in metabolism of DNP, leading to deposition at these sites. Moreover, the lowest concentration was found in heart, which indicates DNP has less perfusion rate in heart. In summary, the distribution of DNP was highest in kidney and lowest in heart.

\section{Conclusion}

The aim of the present study was to develop an assay method for DNP in plasma matrix with simple extraction preparation techniques. Chromatographic separation was achieved on Waters Nova-Pak C18 column $(3.9 \times 150 \mathrm{~mm}, 4 \mu \mathrm{m})$ using isocratic mobile phase of acetonitrile and ammonium formate $(\mathrm{pH} 6.4 ; 0.01 \mathrm{M})(62: 38 \% \mathrm{v} / \mathrm{v})$ at flow rate of $1 \mathrm{~mL} \mathrm{~min}^{-1}$. Solidphase extraction was selected as an optimized method for higher recovery and proper resolution. The assay recovery was $\geq 79 \pm 1.55 \%$ with insignificant matrix effect. The calibration curves in plasma and other tissues were linear in a concentra-

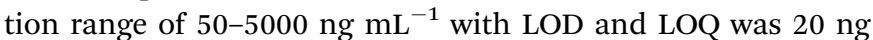
$\mathrm{mL}^{-1}$ and $50 \mathrm{ng} \mathrm{mL}^{-1}$ for plasma samples, respectively. The advantages of the method include simple and rapid sample preparation process, freedom from matrix interference and requirement of small plasma sample volume $(200 \mu \mathrm{L})$, can be applied within a wide concentration range $\left(5000 \mathrm{ng} \mathrm{mL}^{-1}\right)$ and a short total run time (06 min). Experimental plasma concentration-versus-time profiles were fitted to a two-compartmental micro model with i.v. bolus. The tissue distribution studies suggest, that kidney, lungs and liver are the primarily responsible organs for metabolism and elimination of DNP. Moreover, pharmacodynamic studies were conducted by estimating the inhibitory action of AChE was in correlation with pharmacokinetic profile. Our constructive studies provide valuable information to evaluate pharmacokinetic and pharmacodynamic studies for DNP.

\section{Conflicts of interest}

The authors have no conflict of interest.

\section{Acknowledgements}

Mr K. V. Krishna would like to acknowledge University Grant Commission (UGC), India for providing UGC-National fellowship. Vasudha Pharma Chem Limited (Hyderabad, India) is acknowledged for providing the gift samples of DNP and LRD. 


\section{References}

1 K. E. Stuart, A. E. King, C. M. Fernandez-Martos, M. J. Summers and J. C. Vickers, Environmental novelty exacerbates stress hormones and $\mathrm{A} \beta$ pathology in an Alzheimer's model, Sci. Rep., 2017, 7, 2764.

2 M. Prince, A. Comas-Herrera, M. Knapp, M. Guerchet and M. Karagiannidou, World Alzheimer Report 2016 Improving healthcare for people living with dementia. Coverage, Quality and costs now and in the future, 2016, pp. 1-140, https:// www.alz.co.uk/research/world-report-2016.

3 S. A. Eagger, R. Levy and B. J. Sahakian, Tacrine in Alzheimer's disease, Lancet, 1991, 337, 989-992.

4 S. A. Lipton, Paradigm shift in neuroprotection by NMDA receptor blockade: memantine and beyond, Nat. Rev. Drug Discovery, 2006, 5, 160.

5 B. Reisberg, R. Doody, A. Stöffler, F. Schmitt, S. Ferris and H. J. Möbius, Memantine in moderate-to-severe Alzheimer's disease, N. Engl. N. Engl. J. Med., 2003, 348, 1333-1341.

$6 \mathrm{~J}$. C. de la Torre, Alzheimer's disease is incurable but preventable, J. Alzheimer's Dis., 2010, 20, 861-870.

7 J. Bond, C. Stave, A. Sganga, O. Vincenzino, B. O'connell and R. L. Stanley, Inequalities in dementia care across Europe: key findings of the Facing Dementia Survey, Int. J. Clin. Pract., 2005, 59, 8-14.

8 M. Abonassif, M. Hefnawy, M. Kassem and G. Mostafa, Determination of donepezil hydrochloride in human plasma and pharmaceutical formulations by HPLC with fluorescence detection, Acta Pharm., 2011, 61, 403-413.

9 N. Yasui-Furukori, R. Furuya, T. Takahata and T. Tateishi, Determination of donepezil, an acetylcholinesterase inhibitor, in human plasma by high-performance liquid chromatography with ultraviolet absorbance detection, $J$. Chromatogr. B: Anal. Technol. Biomed. Life Sci., 2002, 768, 261-265.

10 M. Bhateria, R. Ramakrishna, D. B. Pakala and R. S. Bhatta, Development of an LC-MS/MS method for simultaneous determination of memantine and donepezil in rat plasma and its application to pharmacokinetic study, $J$. Chromatogr. B: Anal. Technol. Biomed. Life Sci., 2015, 1001, 131-139.

11 M. Noetzli, N. Ansermot, M. Dobrinas and C. B. Eap, Simultaneous determination of antidementia drugs in human plasma: Procedure transfer from HPLC-MS to UPLC-MS/MS, J. Pharm. Biomed. Anal., 2012, 64, 16-25.

12 A. H. Khuroo, S. J. Gurule, T. Monif, D. Goswami, A. Saha and S. K. Singh, ESI-MS/MS stability-indicating bioanalytical method development and validation for simultaneous estimation of donepezil, 5-desmethyl donepezil and 6-desmethyl donepezil in human plasma, Biomed. Chromatogr., 2012, 26, 636-649.

13 M. W. Jann, K. L. Shirley and G. W. Small, Clinical pharmacokinetics and pharmacodynamics of cholinesterase inhibitors, Clin. Pharmacokinet., 2002, 41, 719-739.
14 M. A. Radwan, H. H. Abdine, B. T. Al-Quadeb, H. Y. AboulEnein and K. Nakashima, Stereoselective HPLC assay of donepezil enantiomers with UV detection and its application to pharmacokinetics in rats, J. Chromatogr. B: Anal. Technol. Biomed. Life Sci., 2006, 830, 114-119.

15 K. Nakashima, K. Itoh, M. Kono, M. N. Nakashima and M. Wada, Determination of donepezil hydrochloride in human and rat plasma, blood and brain microdialysates by HPLC with a short C 30 column, J. Pharm. Biomed. Anal., 2006, 41, 201-206.

16 R. Koeber, H.-H. Kluenemann, R. Waimer, A. Koestlbacher, M. Wittmann, R. Brandl, A. Doerfelt, T. Jahner, D. Melchner and E. Haen, Implementation of a cost-effective HPLC/UVapproach for medical routine quantification of donepezil in human serum, J. Chromatogr. B: Anal. Technol. Biomed. Life Sci., 2012, 881, 1-11.

17 US Food and Drug Administration, Guidance for industry, Bioanalytical method validation, http://www.fda.gov/Drugs/ GuidanceComplianceRegulatoryInformation/Guidances/ default.htm, 2013.

18 European Medicines Agency, Guideline on bioanalytical method validation, http://www.ema.europa.eu/docs/en_GB/ document_library/Scientific_guideline/2011/08/ WC500109686.pdf, 2012.

19 K. Yamaoka, T. Nakagawa and T. Uno, Application of Akaike's information criterion (AIC) in the evaluation of linear pharmacokinetic equations, J. Pharmacokinet. Pharmacodyn., 1978, 6, 165-175.

20 L. Parnetti, S. Amici, A. Lanari, C. Romani, C. Antognelli, N. Andreasen, L. Minthon, P. Davidsson, H. Pottel and K. Blennow, Cerebrospinal fluid levels of biomarkers and activity of acetylcholinesterase (AChE) and butyrylcholinesterase in $\mathrm{AD}$ patients before and after treatment with different AChE inhibitors, J. Neurol. Sci., 2002, 23, s95-s96.

21 G. L. Ellman, K. D. Courtney, V. Andres Jr and R. M. Featherstone, A new and rapid colorimetric determination of acetylcholinesterase activity, Biochem. Pharmacol., 1961, 7, 88-95.

22 O. H. Lowry, N. J. Rosebrough, A. L. Farr and R. J. Randall, Protein measurement with the Folin phenol reagent, $J$. Biol. Chem., 1951, 193, 265-275.

23 S. Sharma and R. Taliyan, Synergistic effects of GSK-3 $\beta$ and HDAC inhibitors in intracerebroventricular streptozotocininduced cognitive deficits in rats, Naunyn-Schmiedeberg's Arch. Pharmacol., 2015, 388, 337-349.

24 S. Zhan, B. Ding, Y. Ruan, X. Huang, G. Liu, X. Lv, X. Huang, M. Li, N. Jiang and Q. Shao, A simple blood microdialysis in freely-moving rats for pharmacokinetic-pharmacodynamic modeling study of Shengmai injection with simultaneous determination of drug concentrations and efficacy levels in dialysate, J. Pharm. Biomed. Anal., 2018, 154, 23-30.

25 S. Zhan, W. Guo, Q. Shao, X. Fan, Z. Li and Y. Cheng, A pharmacokinetic and pharmacodynamic study of drugdrug interaction between ginsenoside Rg1, ginsenoside Rb1 and schizandrin after intravenous administration to rats, J. Ethnopharmacol., 2014, 152, 333-339. 